\title{
ESTIMATION OF BALLISTIC PERFORMANCE OF ARMOR STEELS BASED ON THE SPLIT HOPKINSON SHEAR BAR DATA
}

\author{
MAREK WALICKI \\ Military University of Technology, Warsaw, Poland, and \\ Ballistic Laboratory, CFT Precyzja Sp. z o.o., Czosnów, Poland \\ e-mail:m.walicki@cft-precyzja.pl \\ JACEK JANiszeWski, Kamil CiePlaK \\ Military University of Technology, Warsaw, Poland
}

\begin{abstract}
The paper presents a method of assessing of ballistic resistance of four armor steels based on the results of shear tests under dynamic load conditions. All shear tests were performed using a newly developed flat material specimen with two shear zones. High strain-rate experiments were performed using the spilt Hopkinson pressure bar technique. In addition, the V50 ballistic resistance tests for the armor steels were carried out. The maximum value of the shear strain energy density (SSED) was adopted as the evaluation criterion. The SSED parameter takes the highest average value for the armor steel with the highest ballistic resistance.
\end{abstract}

Keywords: split Hopkinson pressure bar, high strain-rate shearing, ballistic resistance, armor steels

\section{Introduction}

A projectile penetrating a metallic armor subjects the material to a complex state of stress that can result in armor failure. There are several types of failure that can occur in metallic armor (Backman and Godsmith, 1978), however many studies focus on the shear plug failure mechanism that is responsible for observed reduction in ballistic resistance of armor steels. Shear plugging is classified as a low energy failure, which can be caused usually by an impact of a blunt-nose projectile or blunt fragments (Cimpoeru, 2016). Many microstructural observations performed on armor steel targets indicate the presence of adiabatic shear bands inside the target (Solberg et al., 2007). Generally, adiabatic shearing is possible if favourable conditions for localised plastic deformation under high strain rate loading exist. When the deformation resulted from the impact occurs so rapidly that thermal softening exceeds the rate of work and strain rate hardening of the target material, then the deformation will localize in narrow zones of intense shear, i.e., adiabatic shear bands (ASBs). In accordance with work (Guo et al., 2020) ASBs are formed in the following steps: stress collapse, strain localization, temperature rise, shear band initiation and crack formation. A necessary condition for the presence of ASBs in a given material is the occurrence of thermo-mechanical instability, which is manifested by a decrease in the plastic flow stress with an increase in the deformation value. Therefore, it is assumed that the development of ASBs in the material begins when the plastic flow stress reaches a maximum, and the corresponding deformation is considered critical $\gamma_{c r}$ (also called instability strain). Hence, the susceptibility of materials to the formation of adiabatic shear bands is often assessed based on the critical deformation value $\gamma_{c r}$ (Bai, 1990).

Generally, shear bands can be classified into two different categories, i.e., deformed or transformed depending on temperature reached in the local area (Xu and Meyers, 2012). Deformed 
bands are formed as regions in the material of intense plastic shear only, whereas transformed bands are zones in which the temperature rise causes a phase transformation.

Shear plug failure is becoming an increasing problem with the increasing strength of the armor material. Generally, the ballistic resistance of an armor steel plate increases with the increase in the hardness of steel. However, in many works (Hazell, 2015) results are presented, which indicate that when the hardness of armor steel increases to a certain level, then ballistic limit velocity begins to decrease. In this case, a failure is observed, which is dominated by localized shear. Hence, it seems reasonable to approach the assessment of ballistic resistance of armor steels based on the assessment of the susceptibility of armor steel to the formation of adiabatic shear bands.

In order to assess the ballistic resistance of an armor steel, various ballistic tests are used, e.g., Depth-of-Penetration Testing (DoP), Ballistic-Limit Testing (V50), Perforation Testing, or the ballistic pendulum test (Zukas, 1990). However, the ballistic resistance determined in this way is not only a function of physical and mechanical properties of the target material, but also, inter alia, of physical and mechanical properties of the penetrator material, impact velocity and projectile geometry, as well as of the thickness and structure of the ballistic shield (monolithic, layered) (Hazell, 2015).

Moreover, the above-mentioned ballistic tests are expensive and complex experiments that require special equipment and laboratory infrastructure. Therefore, the problem is how to test armor steels and base on what quantitative parameters to assess the quality of a given armor steel with respect to its capacity for ballistic protection resulting only from its mechanical properties. In the light of the above considerations regarding the shear plug failure and the formation of adiabatic shear bands during armor penetration, it seems that the results of dynamic shear tests can provide experimental data allowing one to make the right choice of the armor steel grade that shows the best mechanical characteristics in terms of ballistic resistance.

The paper proposes a method of assessing an armor steel with respect to its ballistic resistance based on the results of dynamic tests with the use of a newly developed shear specimen, which was subjected to a dynamic load under the conditions of the split Hopkinson bar test. The maximum value of the shear strain energy density was adopted as the criterion for assessing four types of armor steels, i.e. Armstal 500, Armox 500, Ramor 550 and Armox 600. In light of the results obtained, this parameter has the highest value in the case of the armor steel with the highest ballistic resistance.

\section{Experimental procedure}

\subsection{Armor steels description}

Four types of armor steels were tested: Armstal 500, Armox 500T, Ramor 550 and Armox 600T. All steels belong to the group of high hardness armor steels, which are used both in the structures of bodies of armored vehicles and in panels of ballistic shields mounted on the main armor. The mechanical properties of the steels selected for testing are summarized in Table 1 . The material specimens to be tested were taken from sheets with a nominal thickness of $6 \mathrm{~mm}$.

\subsection{Shear strength tests}

The shear strength tests of the selected steels were performed under quasi-static and dynamic load conditions. Quasi-static tests were carried out using the MTS C45 Criterion testing machine with strain rates of 0.001 and $1 \mathrm{~s}^{-1}$. On the other hand, dynamic shear tests were carried out 
Table 1. Mechanical properties of the tested armor steels (Starczewski et al., 2010; The SSAB Company Website, 2021)

\begin{tabular}{|c|c|c|c|c|c|}
\hline Grade & $\begin{array}{c}\text { Hardness } \\
{[\mathrm{HBW}]}\end{array}$ & $\begin{array}{c}\text { Charpy-V } \\
-40^{\circ} \mathrm{C} \\
{[\mathrm{J}]} \\
\end{array}$ & $\begin{array}{c}0.2 \% \text { Yield } \\
\text { strength } \\
{[\mathrm{MPa}]} \\
\end{array}$ & $\begin{array}{c}\text { Tensile } \\
\text { strength } \\
{[\mathrm{MPa}]} \\
\end{array}$ & $\begin{array}{c}\text { Elongation } \\
A_{5} \\
{[\%]} \\
\end{array}$ \\
\hline Armstal $500[1]$ & $488-566$ & $\min 20$ & $\min 1300$ & 1600 & $\min 8$ \\
\hline Armox 500T [3] & $480-540$ & $\min 32$ & $\min 1250$ & $1450-1750$ & $\min 8$ \\
\hline Ramor 550 [3] & $540-600$ & $\min 16$ & $\min 1550$ & 1850 & $\min 7$ \\
\hline Armox 600T [3], [1] & $570-640$ & $\min 12$ & $\min 1500$ & 2000 & $\min 7$ \\
\hline
\end{tabular}

with the use of the split Hopkinson pressure bar (SHPB) setup, the diagram of which is shown in Fig. 1. The design of the used SHPB is based on a typical design of the SHPB compression test system. The SHPB stand consists of three basic components, i.e., the bar system, the load system and the measuring system. The bar system consists of a set of three bars called respectively the input bar, output bar and striker bar.

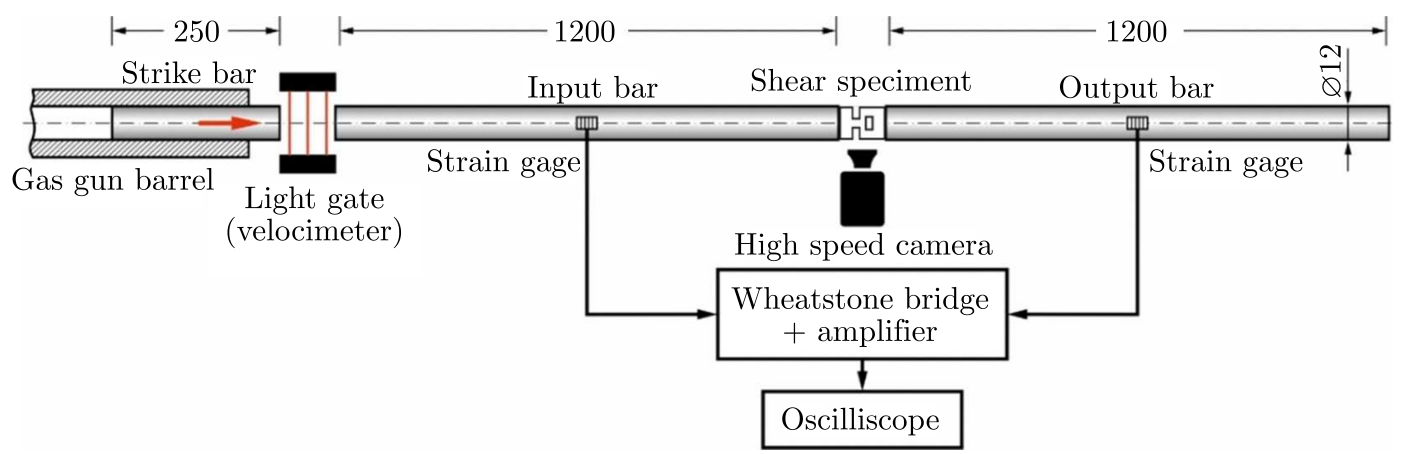

Fig. 1. Scheme of the SHSB setup used in investigations

All bars with a diameter of $12 \mathrm{~mm}$ were made of maraging steel MS350 grade (elastic wave velocity $4866 \mathrm{~m} / \mathrm{s}$ ). The load system consists of a gas gun with an air compressor. This system allows the striker to reach the impact velocity in the range from 5 to $35 \mathrm{~m} / \mathrm{s}$. The basic element of the measuring system of the SHPB stand is a strain gauge measurement system equipped with a strain gauge amplifier with a frequency band of $1 \mathrm{MHz}$ and a digital oscilloscope. Moreover, the SHPB stand is equipped with an optoelectronic measuring system for the impact velocity of the striker bar and a high-speed camera for recording the process of dynamic deformation of specimens.

In order to reduce oscillatory disturbances on the profiles of the shear stress-strain curves, a pulse wave shaper forming a load wave were used. The shapers had a shape of a disc with a diameter of $3 \mathrm{~mm}$ and a thickness of $0.1,0.2$ or $0.3 \mathrm{~mm}$ selected depending on the striker impact speed. All pulse wave shapers were cut out from a copper sheet. Dynamic shear tests were performed for three striker impact velocities, which allowed one to achieve shear strain rate levels averaging approximately: 6500, 10000 and $19000 \mathrm{~s}^{-1}$.

Both quasi-static and high strain-rate shear tests were performed on specimens with a newly developed geometry (Fig. 2a). The shape of the specimen slightly differs from the shape of the shear specimens presented in the literature. In general, two groups of shear specimens are distinguished, i.e., specimens intended for metallographic tests of the shear zone and specimens with well-defined dimensions of the shear zone (Jia et al., 2020). The specimen used in this study belongs to the second group, and the shape and dimensions of the specimen used are the result of experience gained during tests with the use of different shear specimen geometries found in 
the literature. The geometry of the used shear specimen is distinguished by two shear zones, the dimensions of which are defined by the following parameters: width $w$, height $h$ and length $l$ (Fig. 2b), with the shear zone length corresponding to the thickness of the sheet from which the specimens were cut away. The nominal dimensions of the shear zones of the specimens used in the tests are $1 \times 0.8 \times 6 \mathrm{~mm}$, respectively.

(a)

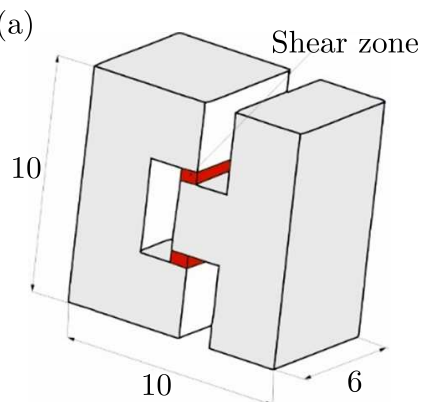

(b)

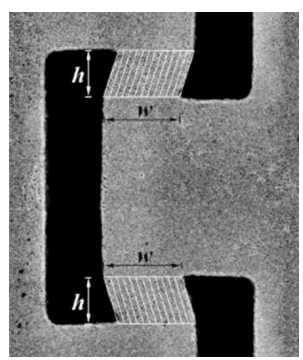

Fig. 2. Shear specimen geometry: (a) scheme with nominal dimensions, (b) markings of shear zone dimensions

The shear stress $\tau(t)$ and the shear strain $\gamma(t)$ as a function of time were determined based on the recorded elastic wave profiles propagating in the input and output bars. Dynamic shear curves were plotted using well-known formulas presented in the literature (Jia et al., 2021). In the case of shear strain, however, the $\gamma(t)$ curve was "calibrated" based on measurements of the shear angle $\theta_{\max }$ just before the occurrence of fracture, which was recorded on high-speed camera images (Fig. 3a). The value of the maximum strain $\gamma_{\max }$ was then calculated based on the arithmetic average of measurements of the angles $\theta_{1}, \theta_{2}, \theta_{3}$ and $\theta_{4}$. This approach towards determining the value of shear strain was forced by the conclusions resulting from the analysis of the stress equilibrium state of the specimen during its shear process. This analysis shows that the stress equilibrium state is achieved only in a narrow range of the specimen shear process (Fig. 3b) and it becomes narrower with the increasing shear rate. Therefore, the lack of an equilibrium stress state generates an error which, according to the performed analyzes, overstates the value of shear strain by about $7 \%$ to $20 \%$ depending on the impact velocity of the striker bar.

(a)

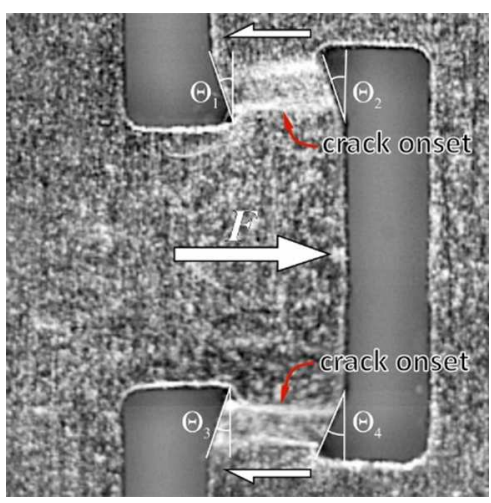

(b)

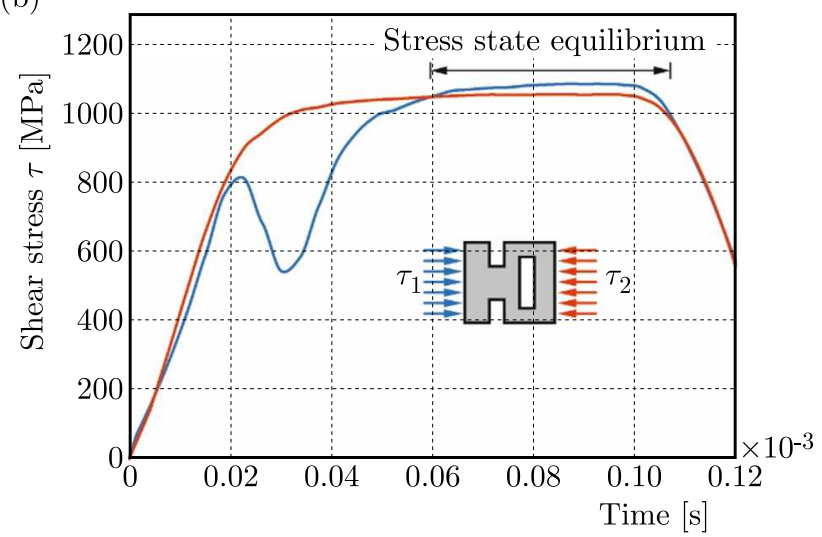

Fig. 3. (a) Scheme of $\theta_{\max }$ measurement; (b) shear stress equilibrium state in the Armox 500T specimen for low impact striker bar velocity $V=12 \mathrm{~m} / \mathrm{s}$

The same method, i.e., with the use of images recorded with a digital camera, was also used to determine the $\gamma_{\max }$ value of the shear specimens deformed under quasi-static loading conditions. In this case, however, it was dictated by the difficulty of accurately determining the $\gamma_{\max }$ value from the shear curves. There were no clear drops in their profiles, i.e., no drop in 
the shear stress corresponding to the moment of shear band formation and the subsequent shear zone fracture. In connection with the above methodology, it was assumed that the determined values of $\gamma_{\max }$ will be treated as the values of the $\gamma_{c r}$ critical strain, also called the instability strain, i.e., a parameter expressing the susceptibility of the material to the formation of ASBs (Bai, 1990; Walley, 2007).

\subsection{Ballistic test}

The purpose of ballistic tests was to determine the ballistic resistance of the tested armor steels. The parameter V50 was adopted as a measure of the ballistic resistance, the values of which were determined for the $7.62 \mathrm{~mm} \times 51$ FMJ NATO ball, in accordance with the test procedure specified in the NATO STANAG 2920 Standard (2015). Ballistic tests were carried out with the use of a material specimen (target) with dimensions of $500 \times 500 \mathrm{~mm}$, cut from metal sheets with a nominal thickness of $6 \mathrm{~mm}$. The specimens had a $100 \times 100 \mathrm{~mm}$ cut-away in one corner, which was made after taking a blank of the base material, intended for making the shear specimens described in Section 2.2. The steel targets were mounted in a special holder, which was a part of the CFT Precyzja Sp. z o.o. ballistic test stand. A schematic diagram of the test rig and a view of the mounted target are shown in Fig. 4. The shooting was carried out from a ballistic barrel, the axis of which was oriented perpendicularly to the target, with a target position uncertainty of $\pm 2 \%$, while the projectile velocity was determined with a measurement uncertainty of $\pm 0.3 \%$.

(a)

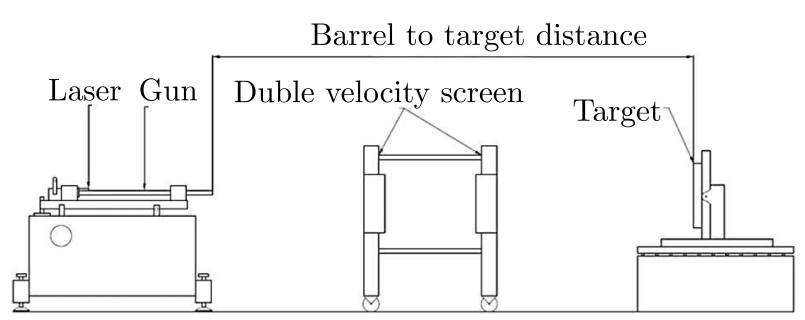

(b)

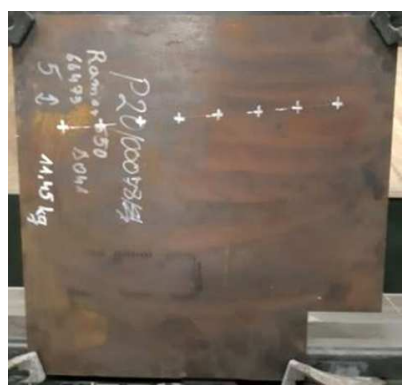

Fig. 4. (a) Scheme of the ballistic test stand, (b) view of the Ramor 550 target mounted

\section{Results}

\subsection{Quasi-static and high strain rate shear testing}

Figure 5 presents photographs of material specimens of the tested armor steel grades after quasi-static shear tests with a strain rate of $0.001 \mathrm{~s}^{-1}$. Based on the shape of the deformed shear zone, it was found that the shear process proceeds in a similar manner in both shear zones; however, their cracking usually occurs at different moments.
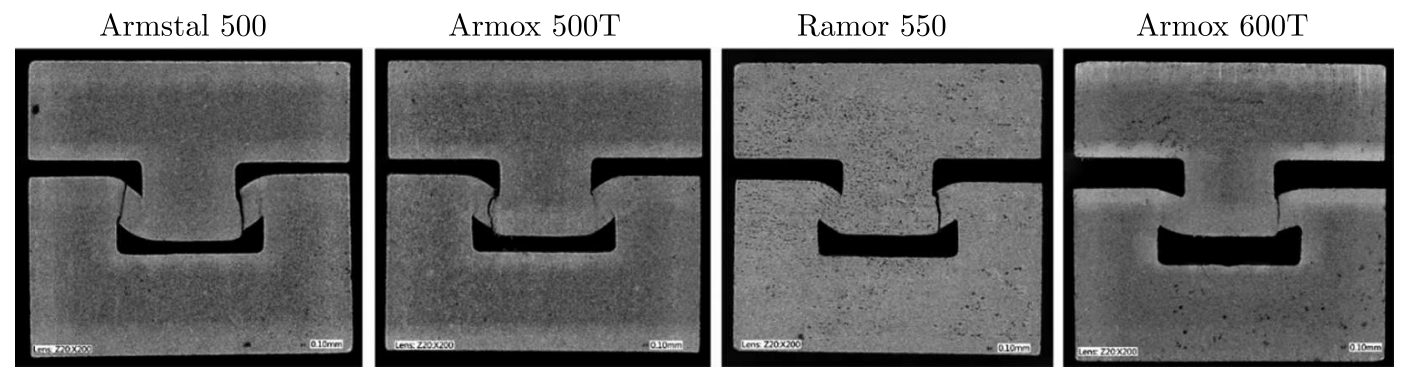

Fig. 5. View of the shear specimens made of the tested armor steels after quasi-static experiments 
Moreover, it was observed that the fracture surface typically adopts a cylindrical contour, and its location is random, i.e., the fracture surface may lie near both the inner and outer boundaries of the shear zone. In all cases of the specimens of the tested armor steels, the crack propagated from the area of the geometric notch located near the rounding formed during the specimen cutting with the EDM method.

The photos of the specimen shown in Fig. 5 also allow one to qualitatively assess the capacity of the tested armor steels for plastic deformation under shear conditions. The highest plastic deformation capacity is demonstrated by Armstal 500 and Armox 500T steels - a high degree of deformation of the shear zone, while the lowest - Armox $600 \mathrm{~T}$ steel.

Optical recordings of the dynamic shearing process made with a high-speed camera reveal a slightly different course of deformation and fracture of the shear zones (Fig. 6). First of all, the similarity in the course of deformation and location of the cracked surfaces in both zones is more visible. Secondly, the cracking onset occurs almost simultaneously in both shear zones - the time difference is not greater than $7.7 \mu \mathrm{s}$. Thirdly, frequent fracture initiation on two surfaces in one shear zone was observed (see Fig. 6 for Armox 500T). However, complete fracture of the shear

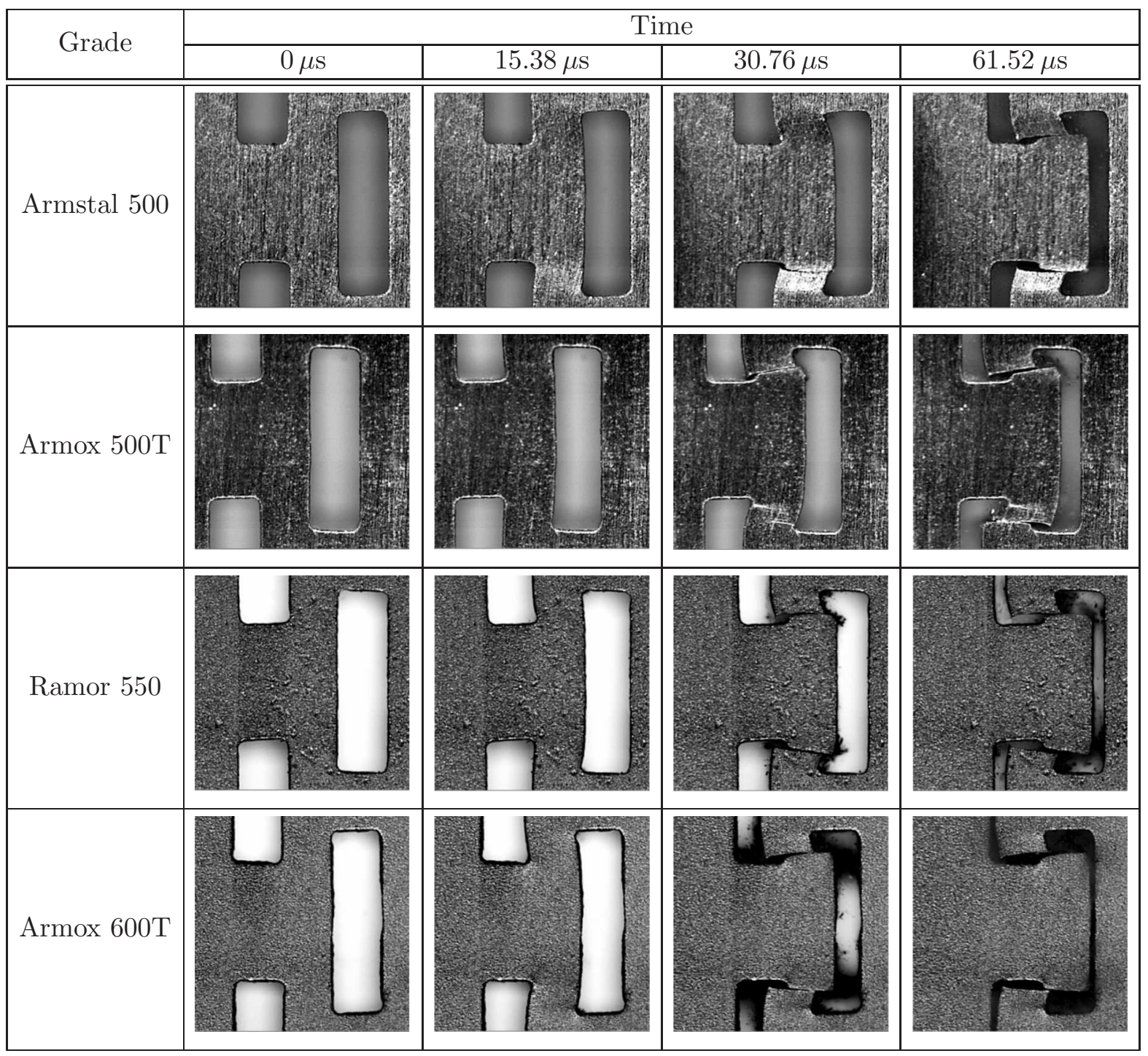

Fig. 6. High-speed video frames illustrating the high strain rate shear deformation and fracture of specimens made of the tested armor steels; experiments with the striker impact velocity of approx $20 \mathrm{~m} / \mathrm{s}$ (recording parameter: resolution $-256 \times 256 \mathrm{dpi}$; frame rate $-130000 \mathrm{fps}$; exposure time $-1.29 \mu \mathrm{s}$ ) 
zone occurred in only one of the surfaces with fracture initiation, while in the other surface, the fracture stopped at different, randomly determined, stages of fracture propagation.

The video frames illustrating the dynamic shear of material specimens (Fig. 6) also allow one to evaluate the plastic properties of the tested armor steels under shear conditions. As in the case of quasi-static tests, the highest dynamic plastic deformation capacity is demonstrated by Armstal 500 and Armox 500T steels, which crack after the longest time since the beginning of the dynamic load impact. In the case of tests with a striker impact velocity of about $20 \mathrm{~m} / \mathrm{s}$ the tested steels cracked after approx $30 \mu \mathrm{s}$. Ramor 550 steel cracked after approx. $28 \mu \mathrm{s}$, whereas Armox $600 \mathrm{~T}$ steel, cracking after about $22 \mu \mathrm{s}$, showed the lowest capacity to plastic deformation under dynamic shear conditions.

In order to quantify the mechanical behavior of the tested armor steels under various shear load conditions, shear curves were developed, which are presented in Fig. 7. Based on them, clear differences in the mechanical response of the tested armor steels can be noticed. The differences occur mainly in the levels of plastic flow stress for individual steel grades. In the case of quasi-static tests, the average stress value corresponding to a strain of 0.2 was $982 \mathrm{MPa}$ for Armstal 500, while for Armox 500T, Ramor 550 and Armox 600T the stress was 971, 1117 and $1319 \mathrm{MPa}$, respectively. Similar relationships are observed in the plastic flow stress levels for a high strain-rate regime. Generally, in all cases of the tested steels, there is a significant increase in the plastic flow stress in relation to the analogous stress determined in the quasi-static test conditions, however, the stress increase resulted from the strain rate sensitivity is different for individual steels. Qualitatively, Armox 500T and Ramor 550 have the highest sensitivity, Armostal 500 slightly lower one and Armox 600T - the lowest one.
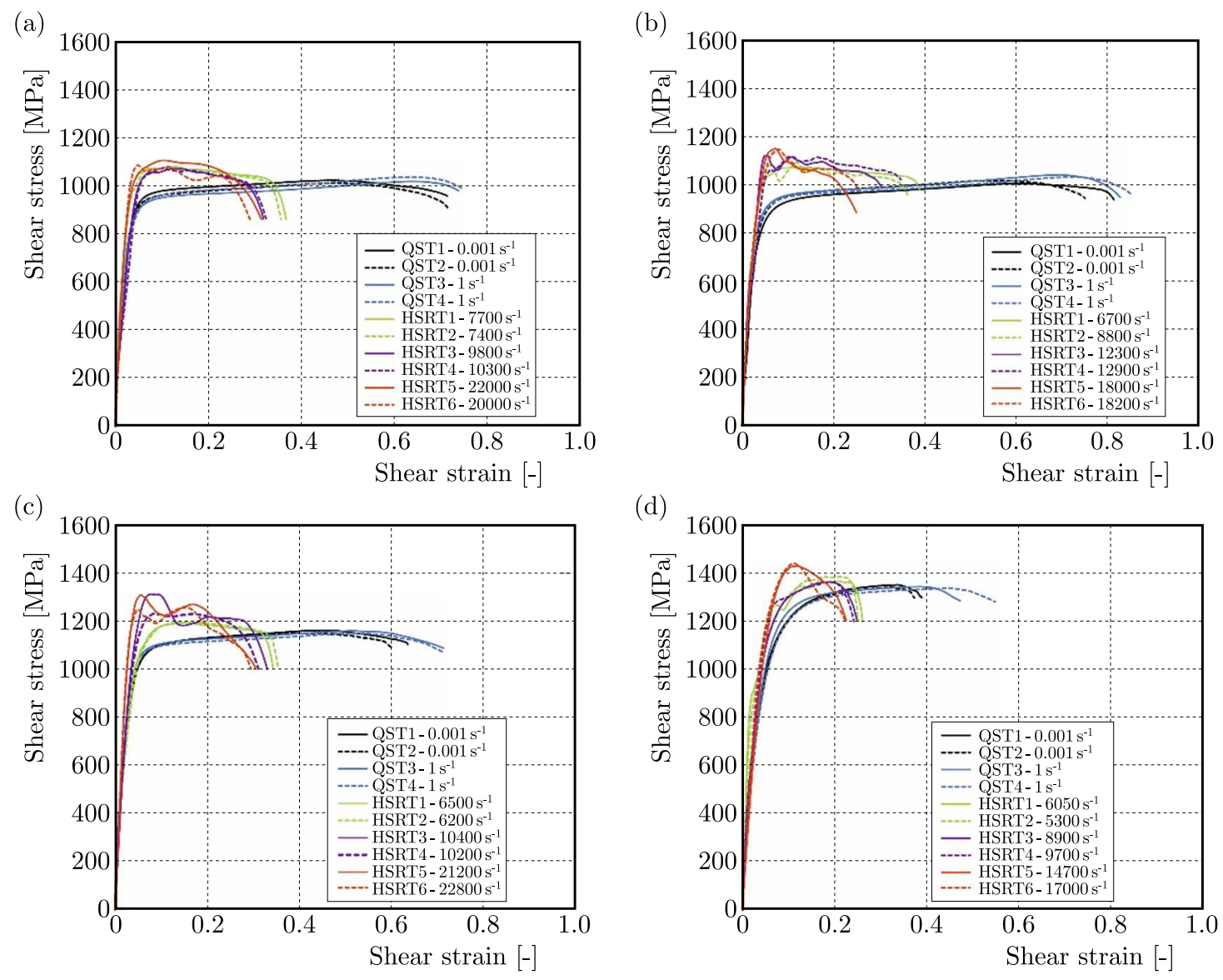

Fig. 7. Nominal shear stress-strain curves for the tested armor steels: (a) Armstal 500, (b) Armox 500T, (c) Ramor 550, (d) Armox 600T 
The shear curves illustrate well the changes in the plasticity of the tested steels as a function of the strain rate. In general, for all cases of armor steels, a clear decrease in plasticity was found with an increase in the strain rate, in particular for the range of high strain rates. The exception are the results of tests carried out with a strain rate of $1 \mathrm{~s}^{-1}$, during which the tested steels showed a slight increase in plasticity (increase in the $\gamma_{\max }$ parameters) - such as Armstal 500 and Armox 500T steels or, like in the case of Ramor 550 steel, or in particular Armox 600T steels - a large increase in plasticity was observed in relation to the test results with a deformation rate of $0.001 \mathrm{~s}^{-1}$. This issue will be discussed in more detail in Section 4 .

\subsection{Ballistic tests results}

Figure 8 shows the view of the targets after firing projectiles of the $7.62 \mathrm{~mm} \times 51$ FMJ NATO ball. The target images show the places of the projectile impact with the test number and the type of damage to the target. The symbol $(+)$ indicates no perforation or partial penetration and the symbol (-) indicates complete perforation of the target.

(a)

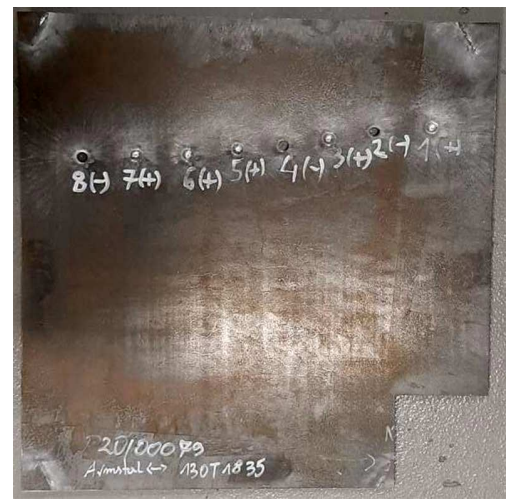

(c)

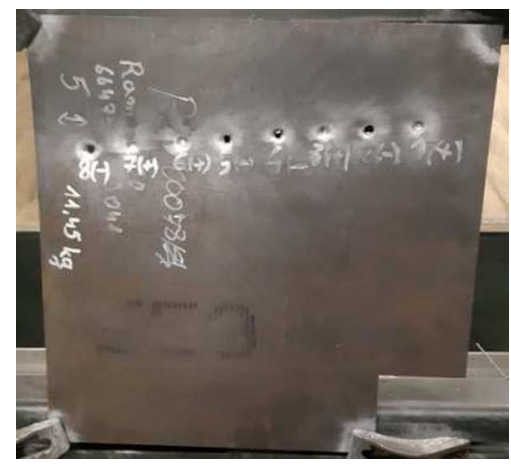

(b)

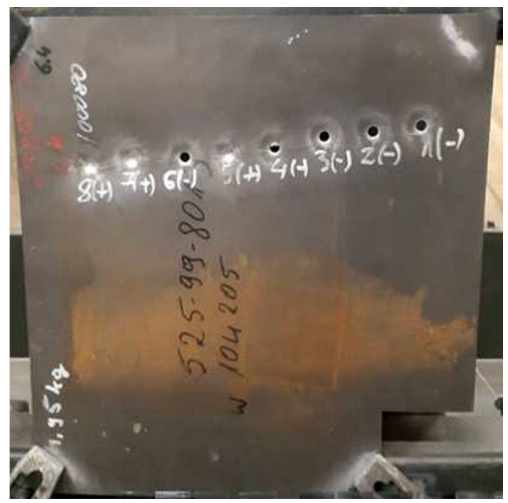

(d)

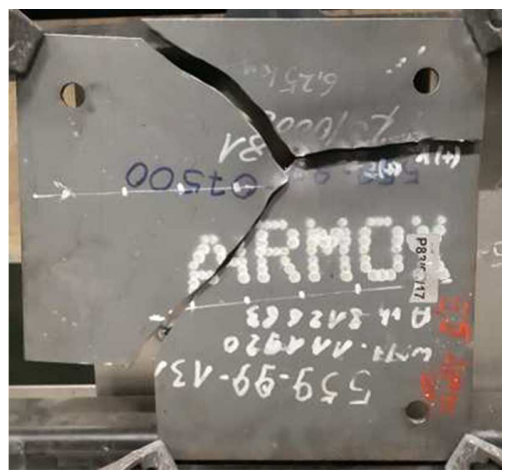

Fig. 8. View of the target plate after ballistic tests: (a) Armstal 500, (b) Armox 500T, (c) Ramor 550, (d) Armox 600T

The surprising result of the ballistic tests is cracking of the target made of Armox 600T steel. Only three shots were fired at it with a projectile velocity of 779,842 and $880 \mathrm{~m} / \mathrm{s}$. In all these cases, the target was not perforated, but only cracked after the third projectile hit it with a speed of $880 \mathrm{~m} / \mathrm{s}$. This is an undesirable phenomenon that disqualifies the target material; however, in the present tests, the specimen target had a corner cut that could initiate a target cracking. Due to the cracking in the target, the ballistic resistance of the Armox 600T target was not determined. In the remaining cases of the tested armor steels, the values of ballistic resistance V50 were determined and summarized in Table 2. The comparison of the V50 parameter values shows that the highest ballistic resistance is shown by Ramor 550 steel and the lowest by Armox 500T, but taking into account the values of the range (Delta) and 
that the thicknesses of the targets were not exactly the same (the Armox 500T target was about $0.15 \mathrm{~mm}$ thinner than the Armstal 500 target), it should be considered that the ballistic resistance of the abovementioned steels is very close.

Table 2. V50 ballistic limit for the tested armor steels

\begin{tabular}{|l|c|c|}
\hline $\begin{array}{c}\text { Armor steel } \\
\text { grade }\end{array}$ & $\begin{array}{c}\text { V50 ballistic limit } \\
{[\mathrm{m} / \mathrm{s}]}\end{array}$ & $\begin{array}{c}\text { Delta } \\
{[\mathrm{m} / \mathrm{s}]}\end{array}$ \\
\hline \hline Armstal 500 & 854.5 & 8.4 \\
\hline Armox 500T & 846.3 & 13.8 \\
\hline Ramor 550 & 880.3 & 6.6 \\
\hline Armox 600T & \multicolumn{2}{|c|}{ not determined (plate cracking) } \\
\hline
\end{tabular}

\section{Discussion}

As mentioned above, the target damage mechanism consisting in the formation of a plug during the impact of a penetrator is closely related to the phenomenon of adiabatic shear band formation in the target material. On the other hand, the susceptibility of the material to the formation of ASBs depends on many factors, which include, among others: thermal conductivity and material density, strain hardening factor, sensitivity to the rate of deformation, or the occurrence of various structural inhomogeneities caused, for example, by different density of structure defects (Xu and Meyers, 2012; Walley, 2007; Yan et al., 2021). Despite the complexity of the phenomenon of the formation of ASBs, simple experimental methods have been developed that allow for the assessment of the susceptibility of the material to the formation of ASBs in it. One of these methods consists in measuring the critical deformation $\gamma_{c r}$ during the shear test (Bai, 1990). Figure 9a presents the curves illustrating the changes in the strain value $\gamma_{\max }$, corresponding to the strain $\gamma_{c r}$ as a function of the strain rate. Based on the shape of these curves, it can be observed that the susceptibility of the tested steels to forming ASBs in the range of low strain rates remains almost constant. Armox 600T steel is an exception here, for which an increase in the $\gamma_{\max }$ strain value was found for the strain rate $1 \mathrm{~s}^{-1}$, which means a decrease in the susceptibility to the formation of ASBs. On the other hand, for a high range of strain rate, i.e. $6000-22000 \mathrm{~s}^{-1}$, a clear increase in the susceptibility to the formation of ASBs in all tested materials is observed, with the lowest value of the $\gamma_{\max }$ parameter shown by Armox 600T steel and the highest value shown by Armox 500T. Armstal 500 and Ramor 550 showed a similar susceptibility to ASBs formation, with the $\gamma_{\max }$ strain values being slightly higher for Armstal 500 steel in the range of low and medium strain rates. Therefore, it can be concluded from the above results and from the previously discussed issues regarding the mechanisms of destroying the armor material (shields) that Armox 500T steel should be characterized by the highest ballistic resistance. Unfortunately, in confrontation with the results of ballistic tests presented in Section 3.2, the above conclusion is not correct, because the highest value of the V50 parameter was shown for Ramor 550 steel.

The lack of correlation between the $\gamma_{\max }$ deformation values of the tested steels for high strain rates and the results of ballistic tests was an inspiration to consider a different approach based on the assessment of the tested steels with respect to the shear strain energy density (SSED), i.e. the ability to absorb deformation energy per unit volume, determined based on the $\tau(\gamma)$ shear curves using the following formula

$$
S S E D_{\max }=\int_{0}^{\gamma_{\max }} \tau(\gamma) d \gamma
$$


(a)

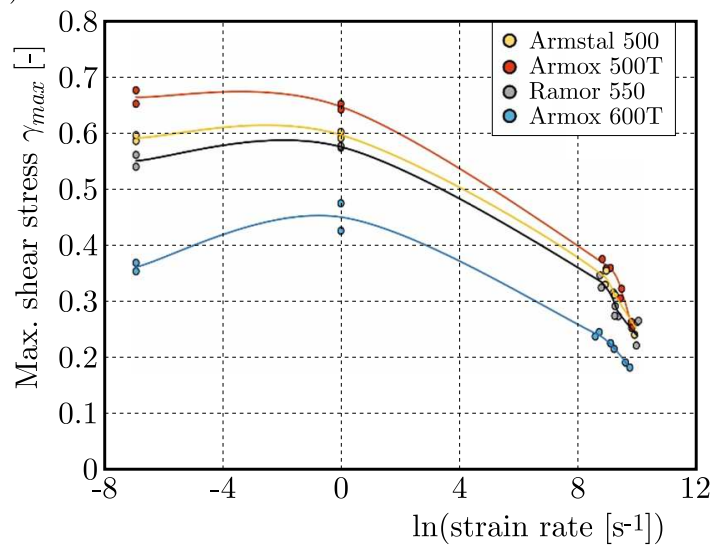

(b)

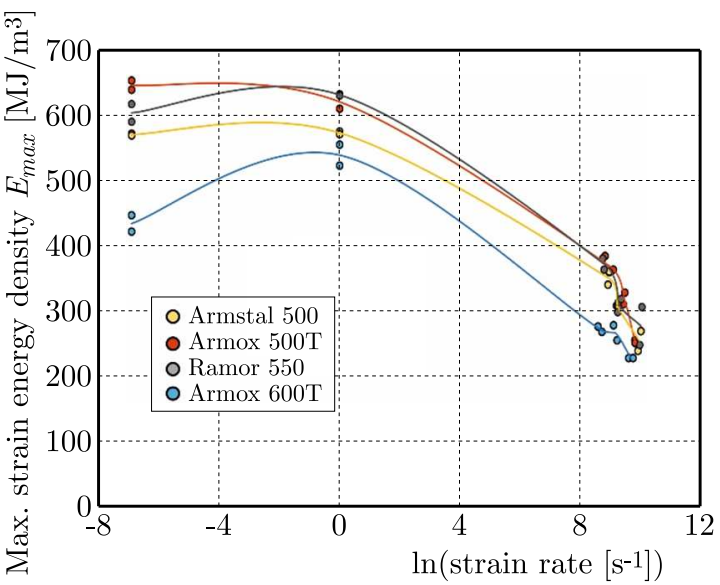

Fig. 9. Graphical representation of the maximum shear strain $\gamma_{\max }$ (a) and the maximum strain energy density $E_{\gamma \max }(\mathrm{b})$ vs. strain rate for the tested armor steels

Figure $9 \mathrm{~b}$ summarizes the changes in the $S S E D_{\max }$ values regarding the shear strain rate achieved during quasi-static and dynamic tests. The summary shows that the highest average $S S E D_{\max }$ parameter values for high strain rates were obtained for Ramor $550\left(321 \mathrm{MJ} / \mathrm{m}^{3}\right)$ and Armox $500 \mathrm{~T}\left(316 \mathrm{MJ} / \mathrm{m}^{3}\right)$, slightly lower for Armstal $500\left(305 \mathrm{MJ} / \mathrm{m}^{3}\right)$, and clearly the lowest for Armox $600 \mathrm{~T}$ steel $\left(257 \mathrm{MJ} / \mathrm{m}^{3}\right)$. As it can be easily seen, the relations in the $S S E D_{\max }$ parameter values among the tested steels correspond very well with the relations determined during ballistic tests. According to Table 2, the highest ballistic resistance was found for Ramor 550 steel, slightly lower for Armstal 500 and Armox 500T, whereas in the case of Armox 600T steel, the target cracked during the shooting. Hence, the above results justify the conclusion that the results of dynamic shear tests with the use of a specimen with a well-defined shear zone can be the basis for assessing the ballistic resistance of an armor steel.

At this point, it should be noted that the armor steel assessing method based on the shear strain energy density $S S E D_{\max }$ is so sensitive that it allows one to assess the ballistic resistance of armor steels whose mechanical properties are very similar, like e.g., Armstal 500 and Armox 500T. From the cognitive point of view, it is also interesting that while clear differences in the $S S E D_{\max }$ parameter values were found in the range of low strain rates for the tested steels, these differences decrease in the range of high strain rates, as it is in the case for Ramor 550, Armox steels 500T and Armstal 500. The reasons for this behavior are currently unknown and will be the subject of further scientific consideration.

The presented method of assessing the ballistic resistance of armor steels is a relatively simple and inexpensive testing procedure that allows one to perform shear tests under standard laboratory conditions, as opposed to ballistic tests. However, it is a method that requires the use of a variety of test equipment (testing machine, non-contact system for measuring geometric quantities, Hopkinson test system) as well as various technical skills and research experience. Due to the methodological correctness of the proposed technique, the key issue is the quality of the material specimen with the precisely defined geometry of the shear zone.

In the case of the specimen used in this study, the shear zones have relatively small dimensions and are located in hard-to-reach places that prevent the use of simple machining technologies. The use of the wire EDM processing enables the shaping of material specimens of complex shapes, however, in the case of miniature shear zones, difficulties arise in maintaining the geometric correctness of the shaped zones. It should be emphasized here that the effort related to reduction of errors in the shape of the shear zone, such as: non-parallelism of the side walls, difference in length of the side walls, too large deviations in the flatness of the side walls, or differences in the size of radius of the rounding undercut adjacent to the shear zone, were among the most complex and labor-intensive. 
In addition, the problem of measuring the shear angle should also be noted. As mentioned in Section 2.2, the shear angle was determined from images captured with a digital camera. As a part of the preliminary tests, the shear angle was initially determined based on direct measurements made on material specimens after the tests had been performed. However, a large scatter in the obtained values of the shear angle was found, which made it impossible to notice differences in the mechanical behavior of the tested steels. The probable cause of the scatter of the measurement results were additional, heterogeneous, and random deformations of the shear zone occurring after the shear zone fracture. This phenomenon, as evidenced by some video recordings, most often occurred during Hopkinson tests, when, after the shear zone had been fractured, its surfaces repeatedly collided with each other as a result of wave loads on the specimen placed between the front faces of the bars. Hence, the method of measuring the shear angle from video images was used, however, also in this case, several difficulties occurred, in particular, during dynamic tests. First of all, due to the fact that the accuracy of the measurement depends on the quality of the recorded images, it was necessary to use a specialized camera lens to record macro images and to use special observation and lighting techniques (combining observation of an object in the reflected light with observation of a object shadow). Secondly, the measurements of the shear angle required the use of software to analyze images recorded with a high-speed camera and the development of a measurement strategy that would guarantee repeatability and objectivity of the measurements.

\section{General conclusions}

The proposed method of assessing the ballistic resistance of armor steels based on the shear strain energy density value or, alternatively, the shear strain energy (based on shear force-shear path curves) seems to be a good alternative to ballistic tests. The main advantage of the above-mentioned method is that it allows for the selection of an armor steel with the most desirable ballistic properties based on the mechanical response of the material, not disturbed by additional effects that occur during ballistic tests (e.g., the influence of the shape or type of projectiles used). The authors share the opinion that the V50 ballistic tests are a very good tool for assessing the ballistic resistance of armor materials to various types of threats. However, in the case of the need to assess ballistic resistance understood narrowly as the mechanical response of the target material to the dynamic load, the proposed method may be a helpful tool for assessing the quality of steel intended for ballistic shields.

\section{Acknowledgement}

This work was co-financed by Military University of Technology in Warsaw under research project UGB.

\section{References}

1. Backman M.E., Goldsmith W., 1978, The mechanics of penetration of projectiles into targets, International Journal of Engineering Science, 16, 1, 1-99

2. BAI Y.L., 1990, Adiabatic shear banding, Res Mechanica, 31, 133-203

3. Cimpoeru S.J., 2016, The Mechanical Metallurgy of Armor Steels Executive Summary, Produced by Land Division Defence Science and Technology Group, Report DST-Group-TR-3305, Commonwealth of Australia, 1-42

4. Guo Y., Ruan Q., Zhu S., Wei Q., Lu J., Hu B., Wu X., Li Y., 2020, Dynamic failure of titanium: Temperature rise and adiabatic shear band formation, Journal of the Mechanics and Physics of Solids, 135, 103811 
5. Hazell P.J., 2015, Armor: Materials, Theory, and Design, CRC Press

6. Jia B., Rusinek A., Pesci R., Bernier R., Bahi S., Bendarma A., Wood P., 2021, Simple shear behavior and constitutive modeling of 304 stainless steel over a wide range of strain rates and temperatures, International Journal of Impact Engineering, 154, 103896

7. Jia B., Rusinek A., Pesci R., Bernier R., Bahi S., Wood P., 2020, A novel technique for dynamic shear testing of bulk metals with application to 304 austenitic stainless steel, International Journal of Solids and Structures, 204-205, 153-171

8. NATO STANAG 2920 Standard, 2015, Ed. 3, Ballistic Test Method for Personal Armor Materials

9. Solberg J.K., Leinum J.R., Embury J.D., Dey S., Børvik T., Hopperstad O.S., 2007, Localised shear banding in Weldox steel plates impacted by projectiles, Mechanics of Materials, 39, $865-880$

10. Starczewski L., Szczech S., Tudyka D., 2010, Tests of armor steels in the aspect of their protection effectiveness (in Polish), Prace Instytutu Metalurgii Żelaza, 62, 110-117

11. The SSAB Company Website. Available online: https://www.ssab.com/products/brands (accessed on 31.09.2021)

12. WAlley S., 2007, Shear localization: A historical overview, Metallurgical and Materials Transactions $A, 38,2629-2654$

13. Xu Y., Meyers M.A., 2012, Nanostructural and Microstructural Aspects of Shear Localization at High-Strain Rates for Materials, [In:] Adiabatic Shear Localization, B. Dodd, Y. Bai (Edit.), 2nd Ed., Elsevier, 111-171

14. Yan N., Li Z., Xu Y., Meyers M.A., 2021, Shear localization in metallic materials at high strain rates, Progress in Materials Science, 119, 100755

15. ZukAs J.A., 1990, High Velocity Impact Dynamics, Wiley-Interscience 